\title{
Storage Temperature Affects Sexual Potato Seed Dormancy
}

\author{
Noël Pallais \\ Department of Physiology, International Potato Center, P.O. Box 1558, \\ Lima, Peru
}

\author{
José Santos-Rojas \\ Instituto Nacional de Investigación Agropecuaria, Casilla 24-0, Remehue, \\ Osorno, Chile
}

Rosario Falcón

Department of Physiology, International Potato Center, P.O. Box 1558, Lima, Peru

Additional index words. Solanum tuberosum, afterripening, seed quality, true potato seed

\begin{abstract}
Sexual potato (Solanum tuberosum $\mathrm{L}$.) seeds require many months of afterripening in dry storage to completely lose dormancy and germinate readily at $>25 \mathrm{C}$. We examined the relationship between storage temperature and seed dormancy, as assessed by the percentage of germination after 4 days. Two $F_{1}$ hybrid lots of 'Desiree' $x 7 X Y .1$ were used; one seed lot was produced by carefully removing half of the developing tubers from the mother plant during seed development, and the control remained undisturbed. Seeds were stored with $3.4 \%$ moisture (dry-weight basis) at 10, 20, 30, 40, and 50C and were tested eight times during 29 months for daily germination at $27 / 40 \mathrm{C}(21 / 3 \mathrm{~h})$ for the first 8 days, followed by 6 days at 17C. After 29 months of storage, final germination was $<97 \%$ only when control seeds were stored at $50 \mathrm{C}$, in which germination was $72 \%$. Germination after 4 days increased curvilinearly with increasing storage temperature, and both seed lots similarly lost dormancy (germination $>90 \%$ ) after 10 months at 40C. Optimum germination levels were maintained after 29 months at $40 \mathrm{C}$. Seeds stored at $50 \mathrm{C}$ never completely lost dormancy, and after 7 months of storage, germination at 4 days gradually decreased to zero. Dormancy was eventually lost after 29 months in most seeds stored at $<40 \mathrm{C}$, and differences between seed lots suggest that removing tubers from the mother plant increased dormancy. We conclude that dry potato seeds can be safely afterripened at temperatures up to $40 \mathrm{C}$; lower temperatures slow the rate of dormancy loss, and higher ones are detrimental to seed quality.
\end{abstract}

Use of sexual potato seeds is increasing as an alternative to seed tubers for propagating potatoes in developing countries (Pallais, 1994). Seeds that germinate readily only at $17 \mathrm{C}( \pm 3 \mathrm{C})$ are considered dormant and not appropriate for sowing a crop of potatoes, whereas nondormant and high-quality seeds germinate readily at $\geq 27 \mathrm{C}$ (Pallais, 1995a, 1995b). Gibberellic acid is not completely effective in promoting uniform germination of dormant seeds and optimum seedling growth at >25C (Pallais et al., 1990, 1991). Potato seed dormancy is released progressively during afterripening in storage, and seeds should always be stored at $<5 \%$ moisture content on a dry-weight basis (Pallais, 1995a, 1995b; Pallais and Espinola, 1992). High storage temperature and low seed moisture content can be used to speed seed dormancy loss during afterripening (Pallais, 1995a, 1995b). Our objective was to determine the relationship between increasing temperature during

Received for publication 17 Jan. 1995. Accepted for publication 10 Oct. 1995. We thank Bill Hardy for his editorial suggestions. The cost of publishing this paper was defrayed in part by the payment of page charges. Under postal regulations, this paper therefore must be hereby marked advertisement solely to indicate this fact. afterripening in dry storage and potato seed dormancy. Removal of developing tubers from the mother plants during seed production was tested as a technique to increase seed quality; therefore, the influence of this effect on the results also was investigated.

\section{Materials and Methods}

This study was conducted at the International Potato Center in Lima, Peru, from Feb. 1992 to Oct. 1994 using two $F_{1}$ hybrid potato seed lots of 'Desiree' $x$ 7XY.1. Seed was produced by hand-pollinations in Osorno, Chile, by the Instituto de Investigaciones Agropecuarias in Apr. 1991, according to the recommended practice for high-quality seed (International Potato Center, 1987). Both seed lots were produced and harvested under similar conditions. In one lot, about half of the developing tubers were carefully removed from the mother plants after pollination (-TUBER), and the other lot served as control (CONTROL).

Seeds had been stored at $\approx 15 C( \pm 5 C)$ for 11 months before the other treatments were started. Seed moisture content, determined with a Sartorious infrared dryer (model YTC01L; Sartorious, Goettingen), at that time was $6.8 \%$ in CONTROL and $7.1 \%$ in-TUBER. A total of $155 \mathrm{~g}$ and $230 \mathrm{~g}$ of CONTROL and -TUBER seeds, respectively, was produced. Each lot was separated with a seed blower (model 1; Hendrickson Enterprises) at threefourths setting into high- and low-density sublots; $48 \%$ of the CONTROL and $53 \%$ of the -TUBER seeds fell in the high-density fraction. Only high-density seeds were used for treatments. Seeds were dried by sealing with fresh silica gel at $22 \mathrm{C}$ until both lots attained $3.4 \%( \pm 0.05 \%)$ moisture content; however, -TUBER seeds took a few days longer than CONTROL seeds to reach this level. Random seed samples sufficient for each evaluation were immediately sealed in separate aluminum packages and stored in temperature-controlled $( \pm 2 \mathrm{C})$ dark incubators at 10 , 20, 30, 40, and 50C.

Evaluations consisted of germination tests conducted at $\approx 3,4,7,10,14,19,24$, and 29 months of storage. Before testing, seeds were humidified to a uniform moisture content of $13 \%$ by placing them in a sealed environment above water at $22 \mathrm{C}$ for $24 \mathrm{~h}$. Germination tests consisted of four replications of 100 seeds each placed evenly over dry Whatman no. 2 filter paper in $9-\mathrm{cm}$ petri dishes. Seeds were hydrated with $5 \mathrm{ml}$ of deionized water before placing them in an incubator at $27 \mathrm{C}$ for $21 \mathrm{~h}$ and at $40 \mathrm{C}$ for $3 \mathrm{~h}$. Although official rules for testing potato seeds are not available, $3 \mathrm{~h}$ at $40 \mathrm{C}$ was included to provide a diurnal stress similar to that which might be encountered by seeds at midday when sown under field conditions. Water was added as needed. On the eighth day of the germination test, temperature was lowered to a constant of $20 \mathrm{C}$; however, 17C was used in the 29-month test. Hydrated seeds usually were placed in the germination environment at the beginning of the $27 \mathrm{C}$ cycle, but in the 14- and 24-month tests, seeds were placed at $27 \mathrm{C}$ for only a few hours before the 3 -h cycle at $40 \mathrm{C}$. Germination was counted daily for 12 days at the first sight of radicle emergence, and for 14 days in the 29-month test. Germinating seeds were exposed to laboratory light and temperature (22C) for $\approx 20$ min during daily evaluations.

Results were summarized by presenting data on 1) germination percentages after 4 days for each germination test, and 2) final germination percentages after 14 days in the 29 -month test. Analyses of variance (ANOVA) were performed after arcsin transformations of the data to determine significance with a completely random design and a two-way factorial arrangement (seed lot $\times$ storage temperature) (Steel and Torrie, 1980). Percentages of germination were presented according to the results of ANOVA and transformed data were submitted to quadratic regression analysis (best-fit model) with storage temperature as the independent variable.

\section{Results and Discussion}

Storage temperature had a profound effect on potato seed dormancy as estimated by the percentage of germination after 4 days at 27/ 40C (Fig. 1). The germination responses to increasing storage temperature were predomi- 

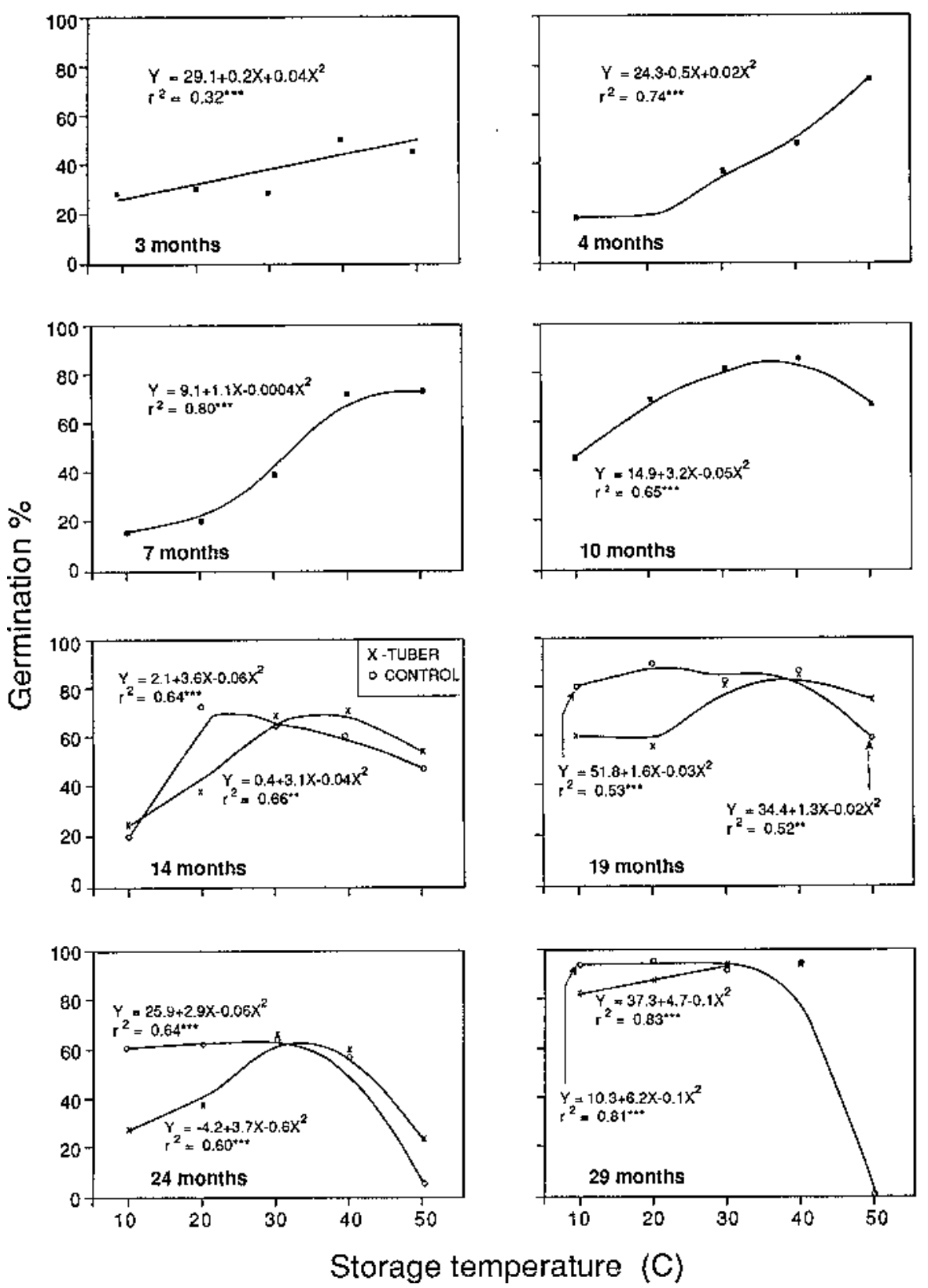

Fig. 1. Effect of storage temperature on percentage of potato seed germination after 4 days at $27 / 40 \mathrm{C}$ (21/ $3 \mathrm{~h}$ ) when tested after $3,7,10,14,24$, and 29 months of storage in two seed lots produced in mother plants with (-TUBER) and without (CONTROL) tubers removed. There were no significant interactions between seed lots in the 3-, 4-, 7-, and 10-month tests, and data of significant $(P<0.05)$ interactions between seed lots were provided for the 14-, 19-, 24-, and 29-month tests. Quadratic regression curves (best-fit model) were generated after arcsin transformations to fit the data. Levels of significance at $P$ $<0.01$ and 0.001 are denoted ss $^{* *}$ and ${ }^{* * *}$, respectively. Seeds were placed in the germination environment at the beginning of the $27 \mathrm{C}$ cycle, except in the 14- and 24-month tests, when seeds were placed under $27 \mathrm{C}$ for only a few hours before the 3 -h cycle at $40 \mathrm{C}$.

nantly curvilinear, and significant interactions between seed lots occurred after 14 months of storage. Most seeds were still dormant after 3 months of storage, as judged by germination levels that were $<50 \%$. Both lots had lost dormancy (germination $>90 \%$ ) similarly after 10 months of storage at 40C (Fig. 1). Germination at 4 days was $>90 \%$ for both lots at 10,19 , and 29 months of storage at 40C. But 50C apparently was detrimental to seed quality because, after 10 months of storage, germination rate declined before it reached optimum levels (Fig. 1). Germination rate gradually increased when seeds were stored at $<40 \mathrm{C}$, and after 29 months only-TUBER seeds stored at 10 and $20 \mathrm{C}$ had not fully attained germination levels of $>90 \%$ (Fig. 1). These results support a previous conclusion that high temperature and low moisture can be used to shorten the period of afterripening required by dormant potato seeds (Pallais, 1995a). More importantly, these results clearly indicate that dormant, dry seeds could be safely afterripened at temperatures up to $40 \mathrm{C}$. Nonetheless, the total germination of dry potato seeds was affected little by storage temperature (Table
Table 1. Effect of temperature during 29 months of storage on percentage of final germination in two potato seed lots.

\begin{tabular}{|c|c|c|}
\hline \multirow{3}{*}{$\begin{array}{l}\text { Storage } \\
\text { temp } \\
\left({ }^{\circ} \mathrm{C}\right)\end{array}$} & \multicolumn{2}{|c|}{ Germination (\%) } \\
\hline & \multicolumn{2}{|c|}{ Seed lot } \\
\hline & CONTROL & -TUBER \\
\hline 10 & 100 & 100 \\
\hline 20 & 100 & 100 \\
\hline 30 & 100 & 100 \\
\hline 40 & 99 & 100 \\
\hline 50 & 72 & 97 \\
\hline $\mathrm{ANOVA}^{\mathrm{z}}$ & Mean square & $P$ \\
\hline Seed lot $(\mathrm{S})$ & 145.6 & 0.0068 \\
\hline Temperature $(\mathrm{T})$ & 9370.9 & $<0.0001$ \\
\hline $\mathrm{S} \times \mathrm{T}$ & 105.3 & 0.0100 \\
\hline Error & 17.2 & \\
\hline
\end{tabular}

${ }^{\mathrm{z}}$ Analysis of variance after arcsin transformation of the data: best-fit model $\mathrm{Q}=$ quadratic component for CONTROL, $\mathrm{y}=83.4+1.8 \mathrm{x}-0.04 \mathrm{x}^{2}, r^{2}=0.84$ at $P$ $<0.001$; and for $-\mathrm{TUBER}$, the regression responses were nonsignificant $(P<0.05)$.

1). After 29 months of storage, final germination was $\geq 97 \%$ for all treatments, except when CONTROL seeds were stored at 50C, then germination was $\approx 25 \%$ lower. These results agree with Simmonds' (1968) observations that potato seed viability is preserved in storage under either cool or dry conditions.

The results also agree with a previous suggestion that potato seed production would be influenced by the stronger sink strength of fast-developing tubers (Pallais, 1987). Seed viability (Table 1) and germination rate (Fig. 1) of CONTROL seeds declined faster than those of-TUBER seeds during storage at 50C. Because a greater resistance to unfavorable storage conditions is used to test for differences in vigor between seed lots (Mathews, 1980), one might conclude that removing tubers from the mother plants should increase the vigor of seeds produced by such plants. However, because seed deterioration is assumed to begin only after seed dormancy is lost (Osborne, 1982; Simmonds, 1968), the results also might be explained if CONTROL seeds were less dormant than -TUBER seeds when the experiment started. This situation was supported clearly by the results of germination at 4 days, when seeds were stored at low temperature (10 and 20C), because germination rate increased more slowly for-TUBER seeds than for CONTROL seeds (Fig. 1) and low temperature preserves potato seed dormancy (Simmonds, 1963). The intensity of potato seed dormancy is positively correlated with tuber dormancy of the mother plant (Simmonds, 1963, 1964), and tuber removal might have increased dormancy-enhancing factors in sexual seeds.

The importance of using only optimumquality seeds for evaluating the potential of this new sexual alternative for propagating the potato crop cannot be overemphasized. After sufficient and proper storage, potato seeds lose dormancy and can germinate very quickly (4 days) at high temperature $(\geq 27 \mathrm{C})$.

We conclude that raising storage temperature to $40 \mathrm{C}$ safely accelerated the rate of dormancy loss in dry potato seeds, whereas storage at 50C was detrimental to seed quality. 
Removal of developing tubers from the mother plants during seed production does not appear to increase seed quality because dormancy was enhanced.

\section{Literature Cited}

International Potato Center. 1987. Annual report CIP 1986-87. Intl. Potato Ctr., Lima, Peru.

Mathews, S. 1980. Controlled deterioration: A new vigor test for crop seeds, p. 647-660. In: P.D Hebblethwaite(ed.).Seedproduction. Butterworths, London.

Osborne, D.J. 1982. Deoxyribonucleic acid integrity and repair in seed germination: The importance in seed viability and survival, p. 435463. In: A.A. Khan (ed.). The physiology and biochemistry of seed development, dormancy and germination. Elsevier, New York.

Pallais, N. 1987. True potato seed quality. Theor. Appl. Genet. 73:784-792.

Pallais, N. 1994. True potato seed: A global perspective. Intl. Potato Ctr. Circ. 20(1):2-3.

Pallais, N. 1995a. High temperature and low moisture reduce the storage requirement of freshly harvested true potato seeds. J. Amer. Soc. Hort. Sci. 120:699-702.

Pallais, N. 1995b. Storage factors control germination and seedling establishment of freshly harvested true potato seed. Amer. Potato J. 72:427436.

Pallais, N. and N. Espinola. 1992. Seed quality as affected by nitrogen during true potato seed production and moisture conditions during storage. Amer. Potato J. 69:85-93.

Pallais, N., N. Fong, R. Falcón, and R. García. 1990.
Factors affecting seedling vigor in potatoes II. Genotype afterripening and pre-sowing treatments. Amer. Potato J. 67:109-119.

Pallais, N., N. Fong, R. Falcón, and R. García. 1991. Improving seedling vigor in sexual seeds of potato under high temperature. HortScience 26:296-299.

Simmonds, N.W. 1963. Correlated seed and tuber dormancy in potatoes. Nature (London) 197:720 721 .

Simmonds, N.W. 1964. The genetics of seed and tuber dormancy in the cultivated potatoes. Heredity 19:489-504.

Simmonds, N.W. 1968. Prolonged storage of potato seeds. Eur. Potato J. 11:150-156.

Steel, R.G.D. and J.H. Torrie. 1980. Principles and procedures of statistics: A biometrical approach 2nd ed. McGraw-Hill, New York. 